\title{
Short communication: Effects of trans fatty acids on markers of inflammation in bovine mammary epithelial cells
}

\author{
P. Rezamand and M. A. McGuire ${ }^{1}$ \\ Department of Animal and Veterinary Science, University of Idaho, Moscow 83844-2330
}

\begin{abstract}
Trans fatty acids (tFA) contribute to inflammation. The objective was to investigate the effects of tFA on mRNA expression of proinflammatory markers in cultured bovine mammary epithelial cells (MAC-T cell line). Bovine mammary epithelial cells were grown in Dulbecco's Modified Eagle Medium containing 10\% fetal bovine serum. Cells were then subcultured in a medium lacking fetal bovine serum, to which incremental concentrations (up to $90 \mu M$ ) of elaidic acid (trans-9 C18:1) or linoleidic acid (trans-9, trans-12 C18:2) were added. Bovine serum albumin (fatty acid-free) solutions were added and cells were collected at specific time points over $48 \mathrm{~h}$. Then, RNA was extracted and converted to complementary DNA for quantitative real-time PCR analysis of proinflammatory gene expression. Presence of elaidic acid caused increases in mRNA expression of interleukin (IL)-1 $\beta$ (3.4-fold; dose-independently over a 6 -h period) and intercellular adhesion molecule (ICAM)-1 (up to 1.4-fold) relative to that for cells treated with no tFA, whereas expression of IL-6 and IL-8 was reduced 0.75- and 0.85-fold, respectively. Presence of linoleidic acid reduced mRNA expression of IL-6 and IL-8 relative to that for control (0.95- and 0.87-fold, respectively). Trans mono- and dienoic fatty acids upregulated mRNA expression of IL-1 $\beta$ and ICAM-1, whereas expression of IL-6 and IL-8 was downregulated in MAC-T cells. Since these genes are ultimately involved in inflammation, elaidic or linoleidic acid, either directly fed or formed in the rumen during biohydrogenation, may alter the risk for mastitis in vivo.
\end{abstract}

Key words: trans fatty acid, inflammation, bovine, mammary

Inflammation affects metabolism and is a common contributing factor in many patho-physiological conditions such as atherosclerosis, insulin resistance, and mastitis (Mozaffarian, 2006). Over the past $20 \mathrm{yr}$, a

Received March 24, 2010.

Accepted October 6, 2010.

${ }^{1}$ Corresponding author: mmcguire@uidaho.edu great deal of information has been generated concerning the relationship among dietary trans fatty acids (tFA), immune function, and inflammatory response. Trans fatty acids are unsaturated fatty acids containing one or more double bonds in the trans configuration. Among these fatty acids (FA), vaccenic acid (trans $11 \mathrm{C} 18: 1)$ is a major tFA found in the rumen as a result of microbial biohydrogenation of unsaturated fatty acids (Wolff et al., 1998). Partial hydrogenation of unsaturated fatty acids can result in production of elaidic acid (trans-9 C18:1) to produce more solid fat. Because a trans configuration for a double bond resembles that of saturated FA, substitution of a FA with a cis double bond can modify cell membrane fluidity, eicosanoid production, and production of a wide range of immune and inflammatory mediators. Greater dietary tFA intake was associated with increases in markers of systemic inflammation via elevated production of proinflammatory cytokines (Mozaffarian et al., 2004a,b; Mozaffarian, 2006). For instance, in patients with known heart disease, positive correlations were observed between erythrocyte membrane tFA content, a marker of dietary tFA intake, and several biomarkers of inflammation including IL-1 $\beta$, IL-6, IL-10, and tumor necrosis factor (TNF) system activity including TNF and soluble TNF receptors 1 and 2 (Mozaffarian et al., 2004b). Increased TNF system activity was observed when dietary tFA intake of healthy individuals increased (Mozaffarian et al., 2004a). The positive association between increased tFA and inflammation may be specific for the tFA isomer consumed. Several studies cited by Mozaffarian (2006) demonstrated an association between increased intake of trans C18:1 and trans $\mathrm{C} 18: 2$ and elevated systemic inflammatory mediators. Findings on the effects of tFA on markers of immune function and inflammation are equivocal. For instance, when human subjects were fed diets enriched in trans-11 and trans-12 C18:1, no significant increases in proinflammatory markers (e.g., TNF- $\alpha$, IL-6, and IL-8) or immune functions (e.g., phagocytosis) were observed compared with subjects fed a diet without tFA (Kuhnt et al., 2007). Nutritional studies in dairy cattle to examine a causal role of increased tFA intake on inflammatory responses are limited. Rodriguez- 
Sallaberry et al. (2007) did not detect an alteration in plasma concentrations of TNF- $\alpha$ or IL- 4 for periparturient cows fed a tFA-enriched diet compared with cows fed a saturated fat-enriched diet. The hypothesis was that gene expression of selected pro-inflammatory markers in bovine mammary epithelial cells (MAC-T) would be upregulated by increased tFA. Therefore, the objective was to determine the effect of trans monoenoic (elaidic acid: trans-9 C18:1) and dienoic (linoleidic acid: trans-9 trans-12 C18:2) FA on the mRNA expression of select inflammatory markers in an in vitro model using a MAC-T cell line.

The MAC-T cells were provided as a generous gift from the laboratory of Gregory Bohach (University of Idaho, Moscow) and grown in Dulbecco's Modified Eagle Medium (DMEM; Gibco/Invitrogen, Carlsbad, CA) containing $10 \%$ fetal bovine serum (Gibco/Invitrogen), insulin $(10 \mu \mathrm{g} / \mathrm{L}$; Sigma-Aldrich, St. Louis, $\mathrm{MO}$ ), and hydrocortisone (48 $\mathrm{\mu g} / \mathrm{L}$; Sigma-Aldrich). Near-confluent $(\sim 80-85 \%)$ MAC-T cells were seeded onto untreated $100-\mathrm{mm}$ plastic dishes at $1 \times 10^{6}$ cells/ dish overnight. Incremental concentrations of elaidic or linoleidic acid (Nu-Chek Prep, Elysian, MN) were prepared by adding a $20 \mathrm{~m} M \mathrm{tFA}$ solution in ethanol to a $0.5 \mathrm{mM}$ solution of fatty acid-free BSA at 33 parts to 1 part (MP Biomedicals, Solon, OH). This solution was vortexed vigorously and added to DMEM (without fetal bovine serum) culture medium in appropriate concentrations for experiments. Concentrations tested were based upon the relation of eladic acid to vaccenic acid (trans-11 18:1) output in milk fat (Mosley and McGuire, 2007) and analysis of elaidic acid concentrations in various plasma lipid pools of lactating cows (Tyburczy et al., 2008). Triplicate dishes were used for each FA concentration and time point. Cells were then washed 3 times with Hanks' Balanced Salt Solution (HBSS; Sigma-Aldrich) and cultured with treatment medium. Control medium contained an equimolar amount of BSA with no tFA. Cells were incubated at $37^{\circ} \mathrm{C}$ and $5 \%$ $\mathrm{CO}_{2}$ for $0.75,1.5,3,4.5$, and $6 \mathrm{~h}$ (short) or 24 and 48 $\mathrm{h}$ (long), and then washed with HBSS. Total RNA was extracted (Qiagen Mini Plus kit with gDNA eliminator column; Qiagen, Valencia, CA) from each culture dish and cDNA was generated using the High Capacity Reverse Transcription Kit (Applied Biosystems, Foster City, CA). Gene expression of IL-1 $\beta$, intercellular adhesion molecule (ICAM)-1, IL-6, and IL-8 was measured in triplicate using a 7500 Fast real-time PCR system (Applied Biosystems) using custom designed TaqMan MGB probes (Applied Biosystems) described previously (Aitken et al., 2009). Glyceraldehyde 3-phosphate dehydrogenase was used as a housekeeping gene in all samples. Primers (forward: GCTACACTGAGGACCAGGTT; reverse: AGCATCGAAGGTAGAAGAGT- a)

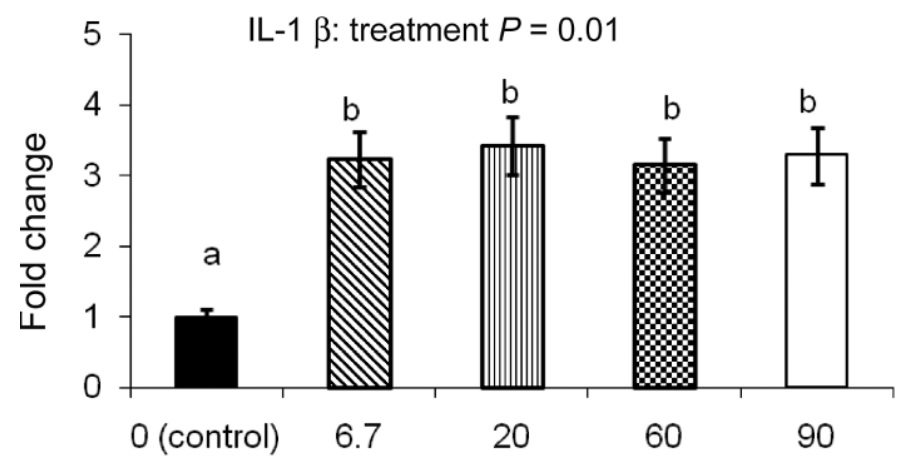

b)

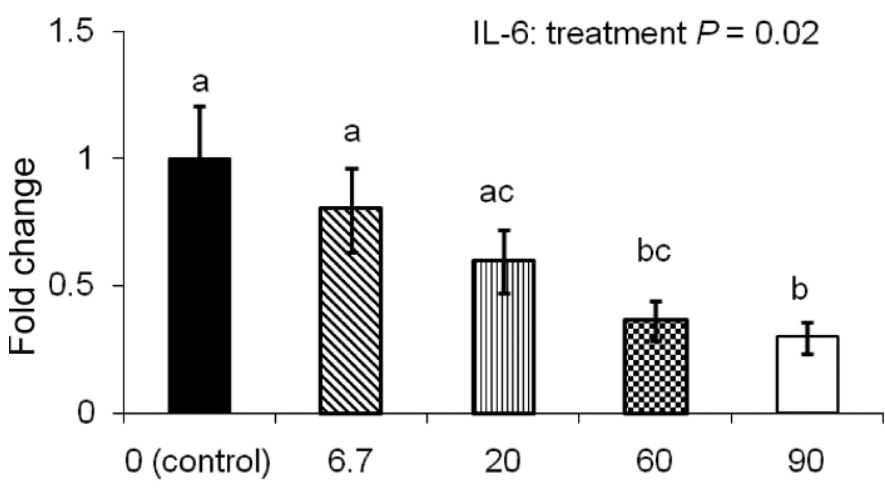

c)

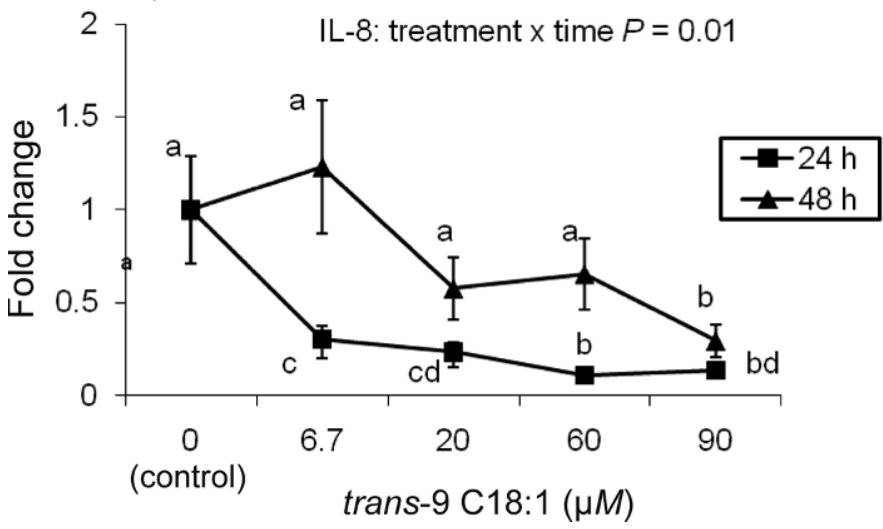

Figure 1. Gene expression (fold change) of inflammatory markers in mammary epithelial (MAC-T) cells exposed to incremental concentrations (0 to $90 \mu M$ ) of elaidic acid (trans-9 C18:1). Original $\Delta$ cycle threshold $(\mathrm{Ct})$ values ( $\mathrm{Ct}$ values normalized with $\mathrm{GAPDH}$ as housekeeping gene) were used for statistical analysis. a) An effect of treatment $(P=0.01)$ was observed over $6 \mathrm{~h}$ on expression of IL-1 $\beta$ mRNA. B) Although no significant effect of treatment was observed over $6 \mathrm{~h}$ on expression of IL-6 mRNA, an effect of treatment $(P=$ 0.02 ) was observed over $48 \mathrm{~h}$. c) Although no significant effect of treatment was observed over $6 \mathrm{~h}$ on expression of IL- $8 \mathrm{mRNA}$, an effect of treatment by time $(P=0.01)$ was observed over $48 \mathrm{~h}$. Means \pm SEM are illustrated in fold change $\left(2^{-\Delta \Delta \mathrm{Ct}}\right.$ method) relative to control (no trans fatty acids). Columns (Figures $1 \mathrm{a}$ and $1 \mathrm{~b}$ ) or points on either the 24- or 48-h line relative to control (Figure 1c) that do not share a similar letter differ $(P \leq 0.05)$. 
Table 1. Gene expression (fold change) of IL-1 $\beta$ in mammary epithelial (MAC-T) cells exposed to incremental concentrations of linoleidic acid (trans-9 trans-12 C18:2) ${ }^{1}$

\begin{tabular}{lcccccc}
\hline & \multicolumn{5}{c}{ Linoleidic acid concentration $(\mu M)$} & Pooled \\
\cline { 2 - 6 } Time $(\mathrm{h})$ & 0 & 6.7 & 20 & 60 & 90 & SEM \\
\hline 0.75 & 1.00 & 1.02 & 0.88 & 1.03 & 1.16 & 0.30 \\
1.5 & $1.00^{\mathrm{a}}$ & $1.85^{\mathrm{b}}$ & $1.62^{\mathrm{a}}$ & $1.79^{\mathrm{b}}$ & $2.99^{\mathrm{b}}$ & 0.54 \\
3 & $1.00^{\mathrm{a}}$ & $2.07^{\mathrm{b}}$ & $2.97^{\mathrm{b}}$ & $1.94^{\mathrm{b}}$ & $2.44^{\mathrm{b}}$ & 0.61 \\
4.5 & $1.00^{\mathrm{a}}$ & $2.48^{\mathrm{b}}$ & $2.77^{\mathrm{bd}}$ & $4.23^{\mathrm{cd}}$ & $4.14^{\mathrm{bd}}$ & 0.85 \\
6 & $1.00^{\mathrm{a}}$ & $1.04^{\mathrm{a}}$ & $2.87^{\mathrm{b}}$ & $2.13^{\mathrm{b}}$ & $3.32^{\mathrm{b}}$ & 0.60 \\
\hline
\end{tabular}

${ }^{\mathrm{a}-\mathrm{d}}$ Values within a row that do not share a superscript differ $(P \leq 0.05)$.

${ }^{1}$ Original $\Delta$ cycle threshold $(\mathrm{Ct})$ values ( $\mathrm{Ct}$ values normalized with GAPDH as housekeeping gene) were used for statistical analysis: overall, a treatment by time effect $(P=0.003)$ was observed over $6 \mathrm{~h}$. Means and the pooled SEM are presented as fold change $\left(2^{-\Delta \Delta \mathrm{Ct}}\right.$ method) relative to control (no trans fatty acids).

GAGT) and the probe (CTCCTGCGACTTCAAC) for GAPDH were designed using Primer Express (v. 2.0; Applied Biosystems). Data were statistically analyzed by using original $\Delta \mathrm{Ct}$ (cycle threshold) values $(\mathrm{Ct}$ values normalized to GAPDH) in the MIXED model procedure of SAS (v. 9.2; SAS Institute Inc., Cary, NC) and significance was determined at $P \leq 0.05$. The 2 culture dishes pooled were considered the experimental unit. The model included effects of treatment (tFA concentration), time and the 2-way interaction. Protected least squares difference was used to compare the means. Means and standard error of means are illustrated in fold change $\left(2^{-\Delta \Delta \mathrm{Ct}}\right.$ method; Livak and Schmittgen, 2001) relative to control (no tFA).

In the current experiment, elaidic acid upregulated (up to 3.4-fold) expression of IL-1 $\beta$ in MAC-T cells in a dose-independent fashion over $6 \mathrm{~h}$ (Figure 1a). Linoleidic acid upregulated expression of IL-1 $\beta$ (Table 1). After $1.5 \mathrm{~h}, \mathrm{IL}-1 \beta$ expression was increased when exposed to as low as $6.7 \mu M$ linoleidic acid. Relative to control (no tFA), the greatest IL-1 $\beta$ expression was observed when cells were treated with 20 to $90 \mu M$ linoleidic acid for $4.5 \mathrm{~h}$.

Elevated IL-1 $\beta$ can affect expression of adhesion molecules such as ICAM-1 (von der Thusen et al., 2003). In agreement, expression of ICAM-1 was elevated with a time by dose interaction (Table 2) when cells were treated with elaidic acid. At $0.75 \mathrm{~h}$ with $90 \mu M$ and at $4.5 \mathrm{~h}$ with $6.7 \mu M$, exposure to elaidic acid caused significant upregulation of ICAM-1. At 3 and 6 h, ICAM1 mRNA expression was decreased. Recently, it was shown that exposure to endotoxin caused upregulation of ICAM-1 in bovine primary mammary endothelial cells as early as $1 \mathrm{~h}$ postchallenge that peaked at $4 \mathrm{~h}$, after which expression of ICAM-1 started to decline (Corl et al., 2008). Relative to mammary gland health, ICAM-1 concentration is increased in blood vessel cells (endothelium) near areas of infection, making the vessel walls "sticky." This attracts immune cells to the site of infection where the immune cells can then detach from the endothelial cells, permeate blood vessel walls, and move to the injured mammary epithelium to aid in the alleviation of infection. In relation to tFA, it was shown that increased tFA intake was positively related to plasma concentration of soluble ICAM-1 and other indices of elevated extravasation in healthy human subjects (Lopez-Garcia et al., 2005). Here, a trend ( $P$ $=0.06$ ) toward significant difference was observed in ICAM-1 expression in MAC-T cells treated with linoleidic acid; the greatest concentration of linoleidic acid used $(90 \mu M)$ was associated with a $51 \%$ upregulation in ICAM-1 mRNA at $6 \mathrm{~h}$ of exposure. Taken together, the results presented here indicate a causal role for both mono- and dienoic tFA within the physiological range promoting an inflammatory status via upregulation of IL-1 $\beta$ and ICAM-1 at the transcription level in immortalized bovine mammary epithelial cells.

Exposure of MAC-T cells to elaidic acid at varying concentrations caused downregulation of both IL-6 and IL-8 (especially with greater concentrations of elaidic acid) over $48 \mathrm{~h}$ (Figure $1 \mathrm{~b}$ and $1 \mathrm{c}$, respectively). Similar results were observed when MAC-T cells were treated with incremental concentrations of linoleidic acid (Table 3).Relative to mammary gland health, IL-6 is an important proinflammatory cytokine involved in regulating appropriate immune response. Elevated IL-6 was detected in both endotoxin-stimulated mammary epithelial cells and in milk obtained from cows with coliform mastitis (Alluwaimi, 2004). Interleukin-8 is produced upon stimulation by bacterial components in many different cell types and is known as a strong neutrophil chemoattractant. Expression of IL-8 was similar in the mammary gland of mid- and latelactation cows, and several stimuli such as endotoxin or Escherichia coli cause significant mRNA expression and protein abundance of IL-8 in mammary epithelial cell lines. In general, positive correlations were found between dietary tFA intake and IL-6 (Mozaffarian et 
Table 2. Gene expression (fold change) of intracellular adhesion molecule (ICAM)-1 in mammary epithelial (MAC-T) cells exposed to incremental concentrations of elaidic acid (trans-9 C18:1)

\begin{tabular}{lcccccc}
\hline & \multicolumn{5}{c}{ Elaidic acid concentration $(\mu M)$} & \multirow{2}{*}{$\begin{array}{c}\text { Pooled } \\
\text { Time }(\mathrm{h})\end{array}$} \\
\cline { 2 - 5 } & 0 & 6.7 & 20 & 60 & 90 & SEM \\
\hline 0.75 & $1.00^{\mathrm{ab}}$ & $1.01^{\mathrm{ab}}$ & $1.08^{\mathrm{ab}}$ & $0.92^{\mathrm{a}}$ & $1.26^{\mathrm{b}}$ & 0.31 \\
1.5 & $1.00^{\mathrm{ab}}$ & $1.35^{\mathrm{a}}$ & $1.12^{\mathrm{ab}}$ & $0.91^{\mathrm{b}}$ & $0.99^{\mathrm{ab}}$ & 0.31 \\
3 & $1.00^{\mathrm{a}}$ & $0.69^{\mathrm{b}}$ & $0.66^{\mathrm{b}}$ & $0.77^{\mathrm{b}}$ & $0.76^{\mathrm{b}}$ & 0.23 \\
4.5 & $1.00^{\mathrm{a}}$ & $1.41^{\mathrm{b}}$ & $1.28^{\mathrm{ab}}$ & $1.15^{\mathrm{ab}}$ & $1.19^{\mathrm{ab}}$ & 0.35 \\
6 & $1.00^{\mathrm{a}}$ & $0.53^{\mathrm{b}}$ & $0.59^{\mathrm{b}}$ & $0.53^{\mathrm{b}}$ & $0.55^{\mathrm{b}}$ & 0.19 \\
\hline
\end{tabular}

${ }^{\mathrm{a}, \mathrm{b}}$ Values within a row that do not share a superscript differ $(P \leq 0.05)$.

${ }^{1}$ Original $\Delta$ cycle threshold $(\mathrm{Ct}$ ) values (Ct values normalized with GAPDH as housekeeping gene) were used for statistical analysis: overall, a treatment by time effect $(P=0.0003)$ was observed over $6 \mathrm{~h}$. Means and the pooled SEM are presented as fold change $\left(2^{-\Delta \Delta \mathrm{Ct}}\right.$ method) relative to control (no trans fatty acids).

al., 2004b; Lopez-Garcia et al., 2005). The tFA examined in the present study caused no detectable alteration in expression of IL-6 or IL-8 up to $24 \mathrm{~h}$, possibly because of infrequent sampling. Another possibility is that the concentrations of tFA examined may not have elicited a strong response from the transcription factor nuclear factor (NF)-IL-6, which in turn would not elicit a response from transcription factor $N F-\kappa B$. It is well established that both of the transcription factors are involved in regulating a wide array of immune cells and acute phase responses at the transcription level including expression of TNF- $\alpha$, IL-6, and IL-8 (Matsusaka et al., 1993). For instance, it was shown that in the absence of NF- $\kappa \mathrm{B}$ or its components, activation of transcription factor NF-IL-6 alone did not result in significant activation of IL-6 at mRNA level.

Addition of the tFA (elaidic and linoleidic acid) to MAC-T cells caused increased expression of IL-1 $\beta$ (maximum of 4.2- and 3.4-fold relative to control linoleidic acid and elaidic acid, respectively) and ICAM-1 (maximum of 1.4-fold relative to control for elaidic acid), whereas IL-6 and IL-8 expression was decreased over a 48-h exposure. Further investigation into the potential effects of tFA on bovine mammary gland health is of great importance because a proinflammatory state during the periparturient period may exist due to an oxidative stress experienced throughout this period (Aitken et al., 2009), and tFA are naturally produced (e.g., trans-11 C18:1) during microbial biohydrogenation of ingested unsaturated fatty acids in the rumen. Currently, cell culture experiments are being undertaken to evaluate the effects of other biologically relevant FA such as conjugated linoleic acid and vaccenic acid on proinflammatory mediators in bovine mammary epithelial cells. Dietary tFA in lactating cattle rations or tFA formation in the rumen during biohydrogenation may alter the risk for mammary gland inflammation.

\section{ACKNOWLEDGMENTS}

Funding for this project was provided by the United Dairymen of Idaho and NIH-NRRI grant P20 RR15587.

Table 3. Gene expression (fold change) of inflammatory markers in mammary epithelial (MAC-T) cells exposed to incremental concentrations of linoleidic acid (trans-9 trans-12 C18:2) ${ }^{1}$

\begin{tabular}{lcccccc}
\hline & \multicolumn{9}{c}{ Linoleidic acid concentration $(\mu M)$} & Pooled \\
\cline { 2 - 6 } Cytokine & 0 & 6.7 & 20 & 60 & 90 & SEM \\
\hline ICAM-1 $^{2}$ & 1.00 & 1.18 & 1.18 & 1.08 & 1.51 & 0.14 \\
IL-6 $^{3}$ & $1.00^{\mathrm{a}}$ & $0.35^{\mathrm{b}}$ & $0.28^{\mathrm{b}}$ & $0.10^{\mathrm{c}}$ & $0.05^{\mathrm{c}}$ & 0.07 \\
IL-8 $^{3}$ & $1.00^{\mathrm{a}}$ & $0.45^{\mathrm{b}}$ & $0.27^{\mathrm{bd}}$ & $0.16^{\mathrm{cd}}$ & $0.13^{\mathrm{c}}$ & 0.08 \\
\hline
\end{tabular}

${ }^{\mathrm{a}-\mathrm{d}}$ Values within a row that do not share a superscript differ $(P \leq 0.05)$.

${ }^{1}$ Original $\Delta$ cycle threshold $(\mathrm{Ct}$ ) values (Ct values normalized with GAPDH as housekeeping gene) were used for statistical analysis. A trend toward effect of treatment $(P=0.06)$ on expression of intracellular adhesion molecule (ICAM)-1 mRNA was observed over $6 \mathrm{~h}$. No significant effect of treatment was observed over $6 \mathrm{~h}$ for expression of IL-6 mRNA; however, an effect of treatment $(P<0.001)$ was observed over 48 h. No significant treatment effect was observed for expression of IL-8 mRNA over $6 \mathrm{~h}$; however, an effect of treatment $(P=$ 0.01 ) was observed over $48 \mathrm{~h}$. Means are presented in fold change $\left(2^{-\Delta \Delta \mathrm{Ct}}\right.$ method) relative to control (no trans fatty acids).

${ }^{2}$ Over $6 \mathrm{~h}$.

${ }^{3}$ Over 48 h. 
The authors thank Katherine Hunt and Janet Williams

(University of Idaho, Moscow) for their technical assistance.

\section{REFERENCES}

Aitken, S. L., E. L. Karcher, P. Rezamand, J. C. Gandy, M. J. VandeHaar, A. V. Capuco, and L. M. Sordillo. 2009. Evaluation of antioxidant and proinflammatory gene expression in bovine mammary tissue during the periparturient period. J. Dairy Sci. 92:589598.

Alluwaimi, A. M. 2004. The cytokines of bovine mammary gland: Prospects for diagnosis and therapy. Res. Vet. Sci. 77:211-222.

Corl, C. M., J. C. Gandy, and L. M. Sordillo. 2008. Platelet activating factor production and proinflammatory gene expression in endotoxin-challenged bovine mammary endothelial cells. J. Dairy Sci. 91:3067-3078.

Kuhnt, K., J. Kraft, H. Vogelsang, K. Eder, J. Kratzsch, and G. Jahreis. 2007. Dietary supplementation with trans-11- and trans-12-18:1 increases cis-9, trans-11-conjugated linoleic acid in human immune cells, but without effects on biomarkers of immune function and inflammation. Br. J. Nutr. 97:1196-1205.

Livak, K. J., and T. D. Schmittgen. 2001. Analysis of relative gene expression data using real-time quantitative PCR and the $2^{-\Delta \Delta \mathrm{Ct}}$ method. Methods 25:402-408.

Lopez-Garcia, E., M. B. Schulze, J. B. Meigs, J. E. Manson, N. Rifai, M. J. Stampfer, W. C. Willett, and F. B. Hu. 2005. Consumption of trans fatty acids is related to plasma biomarkers of inflammation and endothelial dysfunction. J. Nutr. 135:562-566.

Matsusaka, T., K. Fujikawa, Y. Nishio, N. Mukaida, K. Matsushima, T. Kishimoto, and S. Akira. 1993. Transcription factors NF-IL6 and NF-kappa B synergistically activate transcription of the in- flammatory cytokines, interleukin 6 and interleukin 8. Proc. Natl. Acad. Sci. USA 90:10193-10197.

Mosley, E. E., and M. A. McGuire. 2007. Methodology for the in vivo measurement of the $\Delta^{9}$-desaturation of myristic, palmitic, and stearic acids in lactating dairy cattle. Lipids 42:939-945.

Mozaffarian, D. 2006. Trans fatty acids - Effects on systemic inflammation and endothelial function. Atheroscler. Suppl. 7:29-32.

Mozaffarian, D., T. Pischon, S. E. Hankinson, N. Rifai, K. Joshipura, W. C. Willett, and E. B. Rimm. 2004a. Dietary intake of trans fatty acids and systemic inflammation in women. Am. J. Clin. Nutr. 79:606-612.

Mozaffarian, D., E. B. Rimm, I. B. King, R. L. Lawler, G. B. McDonald, and W. C. Levy. 2004b. Trans fatty acids and systemic inflammation in heart failure. Am. J. Clin. Nutr. 80:1521-1525.

Rodriguez-Sallaberry, C., C. Caldari-Torres, W. Collante, C. R. Staples, and L. Badinga. 2007. Plasma prostaglandin and cytokine concentrations in periparturient Holstein cows fed diets enriched in saturated or trans fatty acids. J. Dairy Sci. 90:5446-5452.

Tyburczy, C., A. L. Lock, D. A. Dwyer, F. Destallats, Z. Mouloungui, L. Candy, and D. E. Bauman. 2008. Uptake and utilization of trans octadecenoic acids in lactating dairy cows. J. Dairy Sci. 91:3850-3861.

von der Thusen, J. H., J. Kuiper, T. J. van Berkel, and E. A. Biessen. 2003. Interleukins in atherosclerosis: Molecular pathways and therapeutic potential. Pharmacol. Rev. 55:133-166.

Wolff, R. L., D. Precht, and J. Molkentin. 1998. Occurrence and distribution profiles of trans-18:1 acids in edible fats of natural origin. Pages 1-33 in Trans Fatty Acids in Human Nutrition. J. L. Sebedio and W. W. Christie, ed. The Oily Press, Dundee, UK. 